\title{
Two-Tiered Design Analysis of a Radiator for a Solar Dynamic Powered Stirling Engine
}

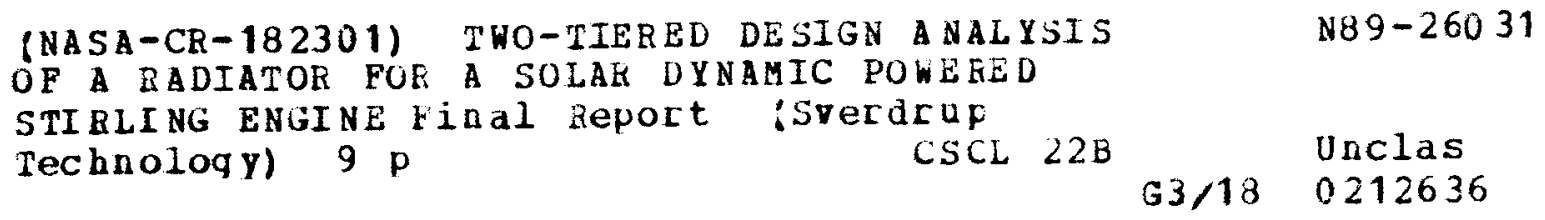

Donald C. Hainley

Sverdrup Technology, Inc.

NASA Lewis Research Center Group

Cleveland, Ohio

June 1989

Prepared for

Lewis Research Center

Under Contract NAS3-25266

\section{N/SA \\ National Aeronautics and \\ Space Administration}


TWO-TIERED DESIGN ANALYSIS OF A RADIATOR FOR A

SOLAR OYNAMIC POWERED STIRLING ENGINE

Donald C. Hainley

Sverdrup Technology, Inc.

NASA Lewis Research Center Group

Cleveland, Ohio 44135

\section{ABSTRACT}

This paper describes a study done using two separate design approaches for a pumped loop radiator used to transfer heat from the cold end of a solar dynamic powered Stiriing engine. The first approach uses a stardard method to determine radiator requirements to meet specified end of mission conditions. Trade-off studies conducted for the analys is are included. Justification of this concept within the specified parameters of the analysis is provided. The second design approach used determines the life performance of the radiator/ Stirling system. In this approach, the system performance was altered by reducing the radiator heat transfer area. Performance effects and equilibrium points were determined as radiator segments were removed. This simulates the effect of loss of radiator sections due to micro-meteoroid and space debris penetration. The two designs were compared on the basis of overall system requirements and goals.

\section{INTRODUCTION}

Thermodynamic principles, as well as physical realities of heat engine design, require waste heat to be rejected from systems employing these conversion devices. The design of radiators to reject this heat is often a very critical issue for a space based power system. Stirling engine power conversion efficiency increases as the cold end temperature is lowered when a constant hot side temperature is assumed. Therefore, a smaller. less massive engine would be required for a specified power level with the lower cold end temperature. However, the area required to radiate heat is inversely related to the heat rejection temperature to the fourth power. These characteristics of the engine and radiator drive an optimal system temperature in opposite directions. Often, the radiator has a more pronounced influence on the system mass.

This paper presents two approaches used in the design of a radiator for the cold end of a solar dynamic Stirling engine power system. The first approach is, the author considers, a standard technique for radiator design. A heat load is specified to be rejected at the end of mission. The radiator size is then determined accounting for an allotted amount of redundancy (additional radiator sections that work in paralle 1 with the rest of the system). Extra heat pipes in a radiator and parallel pumped loops are radiator components that are considered redundant. The extrasegments allow portions of the radiator to become inoperative due to penetrations by micrometeoroids and space debris while having no affect on the meeting of system requirements. A radiator is designed to meet certain probability of survivability requirements. The use of redundancy allows the overall survival requirements of individual components to be reduced due to "extras" being available. This decreased survival condition reduces the required amount of protective material (armor) needed on the radiator. This in turn allows a smaller temperature drop through this armor and therefore, a smaller radiator would be needed (not including the redundant segments). Initially, more redundancy in a radiator allows its total mass to be reduced due to a reduction in the required armor thickness. A point is reached where the extra component mass is not offset by the overall mass savings obtained by the system. Thus, a minimum radiator mass is a function of the redundancy as well as other radiator characteristics.

In the above approach, a radiator is initially oversized thermally to meet the heat transfer requirements. Additional area exists at the beginning of the mission that is capable of being used for heat.transfer. The second approach discussed in this report thermally sizes the radiator initially to just meet the heat transfer requirements (i.e., no redundancy), but determines the armoring thickness as though redundancy existed. This approach uses the effect of redundancy to its maximum advantage. The armor thickness, and therefore the radiator mass, will be reduced due to the assumed redundancy and lower. design heat transfer requirements. The lessened armor thickness will also reduce the required radiator size due to the lower thermal resistance to heat transfer through the armor. As radiator sections become inoperative, the radiator heat transfer capability is reduced due to the lack of excess area being available that could be used. Therefore, as this occurs, assuming the characteristics of the solar dynamic system have remained constant, an increased radiator and stirling engine cold end temperature will be realized and with it, a reduced engine electrical output. This low end temperature will continually be adjusted upward as more radiator area becomes inoperative resulting in a decrease in the engine efficiency. The engine performance will thus be a function of radiator segment life. If a system can withstand some amount of degradation in its life, even for a short while until the 
radiator area can be restored, this design approach may offer a substantial saving in radiator mass. Another possibility in system planning is to overdesign the solar dynamics collector, receiver, and power conversion engine and use a parasitic load resistor to dissipate excess energy that may not be required by the system initially. Then, as segments of radiator area are destroyed, engine performance will decrease and the resistor will have to dissipate less energy to meet the basic system needs.

This paper describes the two design methods in more detail for a specific design situation. Comparisons are made of the two approaches and conclusions made from the results.

\section{REQUIREMENTS}

An effort was undertaken to design a waste heat radiator for a short duration, space solar dynamic/Stirling engine experiment. This initial concept was specified to be a rigid system limited in size to fit in the space shuttle. A cylindrically shaped, pumped loop radiator, approximately $12 \mathrm{ft}(3.658 \mathrm{~m})$ in diameter to roughly match the calculated solar dynamic concentrator size was used for the design. The basic configuration shown in Fig. I was assumed.

Allowance was made for radiation from the cylindrical radiator inner surface to the area not occupied by the solar dynamics collector. A view factor from the cylinder inside surface to space was determined to be approximately 0.39 . No additional credit or penalty was assumed for the heat transfer capability of the radiator due to the presence of the solar dynamics concentrator. However, due to its position, only micrometeoroids and debris originating from one of the cylindrical base openings was considered to impact upon the inner radiator surface. The solar dynamic concentrator was assumed to block any particles that would originate from the direction opposite the "open" cylinder base.

The stirling engine was required to produce $1.5 \mathrm{~kW}$ of electricity. The hot end was specified to be at $1000 \mathrm{~K}$. Table I contains the temperatures and heat transfer values specified as characteristics of the Stirling engines and radiators considered for this analysis.

A 1 year mission life with a 99 percent probability of survivability was chosen for the radiator system. The altitude was chosen to be $1000 \mathrm{~km}$ to obtain a high debris flux environment. A $250 \mathrm{~K}$ sink temperature was also assumed. A segmented, pumped loop radiator was selected for the analys is using a mixture of ethylene glycol and water at a pressure of $3.0 \mathrm{MPa}$ as the working fluid. This mixture and pressure was chosen to ensure the radiator would not freeze prior to the experiment commencing.

\section{STANDARO DESIGN METHOD}

\section{Approdch}

A number of parameters were examined to determine their affect on system mass and to minimize it. Due to the assumed radiator configuration, it was decided to make the system in either 3 or 6 independent radiator sections (panels). The number of radiator sections and the number of sections required to survive were varied. The effect of varying the transport duct and connecting tube (the tubes between the transport ducts) diameters, fin thicknesses, and the number of connecting tubes per radiator panel was examined. Aluminum, titanium, and niobium were used to determine a minimum mass system. Two different temperature drops experienced by the radiator were examined. This temperature change represents the fluid temperature rise that occurs as it travels through the Stirling engine and extracts heat from it. A 5 and $10 \mathrm{~K}$ temperature change were used in the determination of a minimum mass radiator. The temperatures listed in Table I were used as the mean temperatures that had to be met by the fluid in the engine.

\section{Results}

The standard design method assumes a radiator that must meet a specified heat load at the end of its life. This design was required to withstand the heat load stipulated by the engine characteristics stated in Table I while the aforementioned variables were changed in order to determine the minimum mass configuration. Figure 2 shows the optimized radiator masses using the standard design approach for the engines in Table 1 . The characteristics shown in Tables II and III represent the minimum mass/configuration details for the temperature ratios of 2 and 3 for this design approach.

The radiator mass decreased with decreasing header diameter, connecting tube diameter, and fin thickness. The analysis did not allow any material thickness variables to decrease below 0.0005 meter due to assumed manufacturing limits. Any change in these limits will have a direct effect on the system mass. A significant factor in the radiator mass is the fin contribution. A reduction in this limit may greatly decrease the radiator mass. Simple pressure stresses in the header and connecting tube material were also determined and are safely within allowances for the radiator design.

Total optimized radiator mass varied from 25.7 to $10.2 \mathrm{~kg}$ for the temperature ratios chosen. In comparison with the rest of the system, these masses are very low and on the same order as the stirling engine mass. Therefore, for this design, the radiator does not constitute the largest contributor to system mass as is often the 
case. This was considered sufficient reasoning to allow the choice of any temperature ratio that would be used for additional analysis. A temperature ratio of three was chosen for further analys is due to the higher engine efficiency existing at this point.

\section{LIFE PERFORMANCE METHOD}

\section{Approach}

After the initial analysis had been completed, the radiator was analyzed using the life performance approach. The basic premise was to thermally design a radiator with no redundancy, but make the armoring thickness sufficient to guarantee that only a certain percentage of the radiator survive the mission. Using the parameters of this andysis as an example, if the radiator was a six panel configuration at a temperature ratio of 3 , then it would be designed to be capable of rejecting the $2.60 \mathrm{~kW}$ of heat. However, the armoring on the radiator would be designed, for instance, on the assumption that possibly 4 of the 6 radiator panels may become inoperative during the mission.

The engine and radiator are sized for a particular temperature ratio. Initially, with all radiator panels intact, the engine will operate at full power. Due to the radiator armoring thickness, panels are expected to be lost during the mission. As this occurs, the engine cold end and radiator will adjust themselves and operate at off-design conditions. The remaining radiator will not be able to reject all the heat and the temperature of the engine and radiator will rise. At some point, the remaining radiator and engine will come into equilibrium. The engine temperature and radiator temperature and temperature change will be larger than those values associated with the initial thermal design point. Allowing the radiator to be sized with this "pseudoredundancy" in mind will produce a radiator that is significantly lighter than would occur if all panels were required to exist for the entire mission life. It should be noted though, as radiator sections become inoperative, the actual engine output will not remain at the initial $1.5 \mathrm{~kW}$ level nor will the radiator heat load remain at the $2.6 \mathrm{~kW}$ value. The engine output will fall due to a decrease in engine efficiency while the required radiator heat load will increase.

\section{$\underline{\text { Results }}$}

The minimum mass configuration of the standard method design analysis was initially used as the basis for the life performance method. The number of connecting tubes determined from the standard approach was varied to determine a new minimum mass system. Therefore, connecting tube and header diameters, number of panels (6), and materials are the same for the two methods (at the temperature ratio of 3 ).

Work was done to size the radiator so that initially only $2.6 \mathrm{~kW}$ of heat would be rejected. An additional, self-imposed, constraint was added. The radiator temperature would not go above $500 \mathrm{~K}$ for the mission as panels were destroyed. This was done due to account for the significant strength reduction of aluminum at higher temperatures. Several design iterations were done to determine the new system equilibrium temperature as radiator panels were destroyed. Off-design engine performance was determined by assuming an engine efficiency of 55 percent of Carnot at the temperature ratio of 3 . A linear variation of this efficiency was assumed to a value of 45 percent of Carnot at a temperature ratio of 2 . The final design allowed 4 of the 6 original panels to be destroyed through the mission duration. The specific design details are shown in Table IV.

The engine/radiator equilibrium conditions were determined as radiator panels became inoperative. Those results are presented in Fig. 3.

\section{COMPARISON OF RESULTS}

As can be seen from Tables II and IV, the life performance design approach has a mass that is only 58 percent of that determined by the standard approach (for an inltial temperature ratio of $3)$. This is at the expense of a 31 percent degradation of engine performance over the radiator life. The same basic design requirements were examined for other mission lengths. A 10 year 1 ife case resulted in a mass reduction of 55 percent using the life performance method. Therefore, in this case, one fallure would be expected to occur approximately every $2-1 / 2$ years. At this time, a 5 percent drop in the engine performance would occur. This may represent a small enough value to be accommodated in remaining system design, or a design could assume a defective section will be replaced by astronauts within a specified time period.

The use of higher fluid flow rates in order to increase heat transfer from the radiator as panels were destroyed was also examined for the life performance method. Calculations were done in order to determine the mass flow required to maintain the same temperature ratio. The results did not prove to provide an acceptable solution. Decreased engine capability due to the significantly higher pumping power requirements would be required for this situation.

A more correct comparison of the two radiator design methods is one in which the similar heat transfer requirements exist for the same mission length. The same basic radiator panel designs that were established as the optimum configurations for the two design methods were used for this part of the analysis. Due to the life performance approach having four "extra" panels, it is assumed that the rate of loss of a radiator panel is one-quarter of its mission length. Therefore, to produce equivalent specifications, the life performance radiator design was required to survive for four times the mission length specified for the standard radiator design. This is to ensure that the heat load will be carried for the entire mission life determined for the basic design approach. Figure 4 demonstrates the effect of varying thermal loads on the radiator mass while 
Fig. 5 displays the effect of mission length on radiator mass for a fixed thermal load for the two "equivalent" designs. These two figures show that a substantial mass savings may be achieved with the use of a life performance design approach.

\section{CONCLUSION}

A Stirling engine/solar dynamics radiator has been designed using two different techniques. The optimized radiator mass ranges from 10.2 to $25.7 \mathrm{~kg}$ for temperature ratios of 2 and 3 respectively for a standard design analysis. The design used aluminum with an esnissivity of 0.85 and assumed a $10 \mathrm{~K}$ temperature drop through the radiator. The radiator was composed of 5 independent radiator sections. Due to the radiator mass relative to the remaining system, the 3.0 temperature ratio was used as the baseline design.

The second method used resuits in a radiator design that also meets the stirling engine requirements with a 3.0 temperature ratio. The radiator meets the heat rejection requirement with all panels operational at beginning of 1 ife but allows 67 percent of the area to be destroyed during the mission. This resulted in a much lighter design at the expense of 31 percent decrease in power output over the system life. The resulting mass determined was $14.9 \mathrm{~kg}$.

A comparison of the two design approaches shows interesting results. When the same requirements are mandated for the two designs, the life performance design approach yields a radiator that is approximately 30 percent less massive than the standard design method. The explanation is coupled to several factors that have gone into the analyses. The basic approach initially oversizes

TABLE I. - ENGINE AND RADIATOR SPECIFICATIONS AT VARIOUS TEMPERATURE RATIOS

\begin{tabular}{|c|c|c|}
\hline $\begin{array}{c}\text { Temperature } \\
\text { ratio }\end{array}$ & $\begin{array}{c}\text { Engine cooler } \\
\text { temperature, } \\
\mathrm{K}\end{array}$ & $\begin{array}{c}\text { Required } \\
\text { heat to be } \\
\text { radiated, } \\
\mathrm{kW}\end{array}$ \\
\hline 3.00 & 333 & 2.60 \\
2.75 & 364 & 2.79 \\
2.50 & 400 & 3.13 \\
2.25 & 444 & 3.60 \\
2.00 & 500 & 4.16 \\
\hline
\end{tabular}

a radiator thermally. This effect is carried through to determine the required radiator protective armor. The larger area requires more armor which, in turn, reduces the heat transfer capability. The life performance approach takes all the excess out of an initially sized radiator. Although such a system is theoretically required to have a much longer mission life to meet the same system needs, the smaller size and more "extra" sections reduce the radiator mass considerably.

It may be argued that as one section of a radiator designed by the life performance technique is destroyed, the entire system capabilities will be reduced, whereas with the standard approach system performance will still be capable of meeting a set of minimum requirements. Although this is true. it is believed that a system can be designed to accommodate this situation without a substantial increase in system mass. Additionally, due to conservatisms involved in prediction of failure due to micrometeoroid and space debris impact, a part may last much longer than anticipated theoretically. This fact would lean one toward the use of a life performance radiator design approach.

The life performance method presented offers a designer another option by which a radiator and system can be fashioned and optimized.

The specific solar dynamic/stirling experiment design described was an elementary, first attempt to configure a flight demonstration of the system assuming the use of the space shuttle. Additional work is being done at the NASA Lewis to explore other possibilities for such an experiment.

TABLE II. - RADIATOR DETAILS FOR TEMPERATURE RATIO = 3

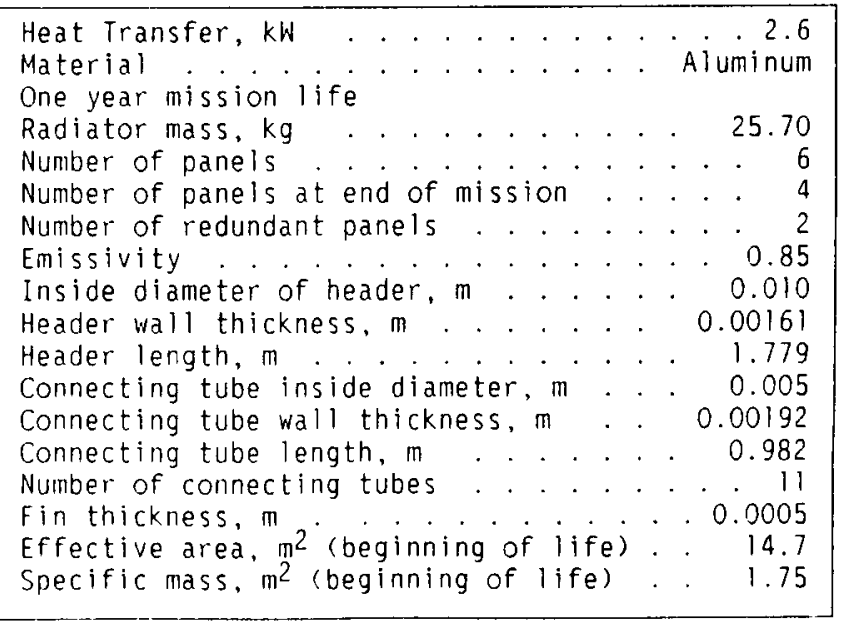




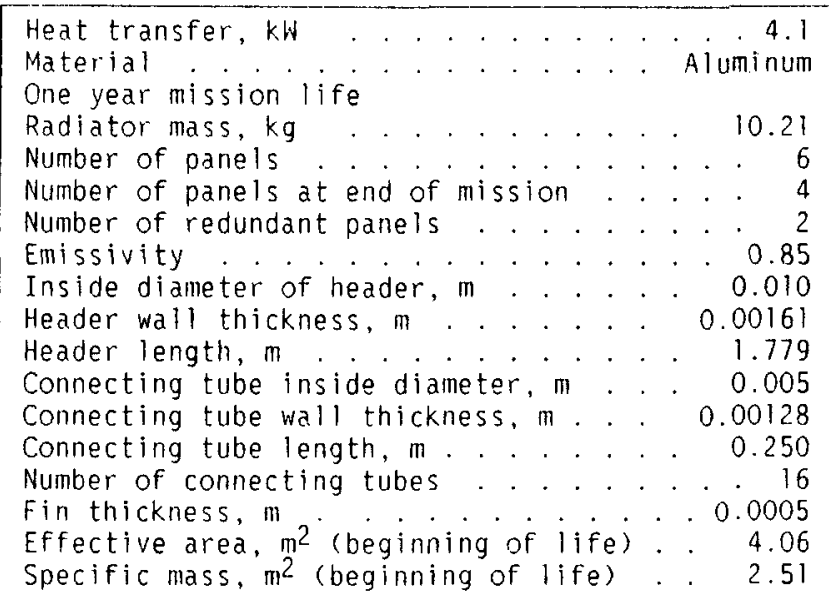

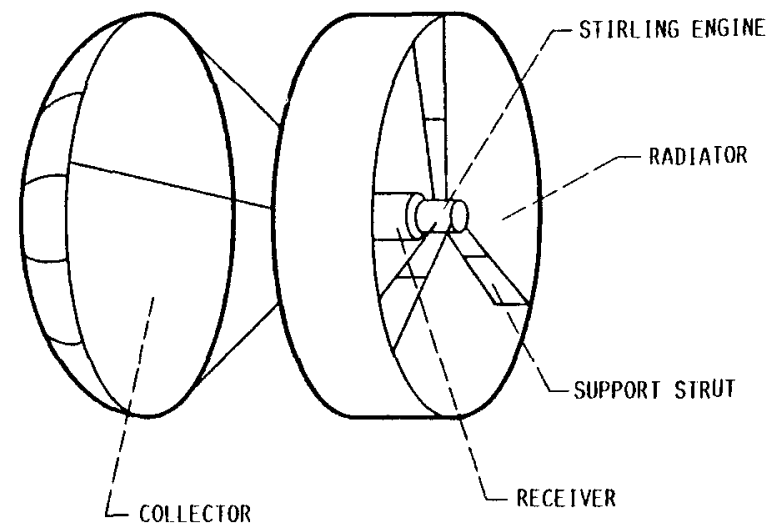

FIGURE 1. - SCHEMAIIC REPRESENINTION OF SYSIEM CONF IGURAIION.

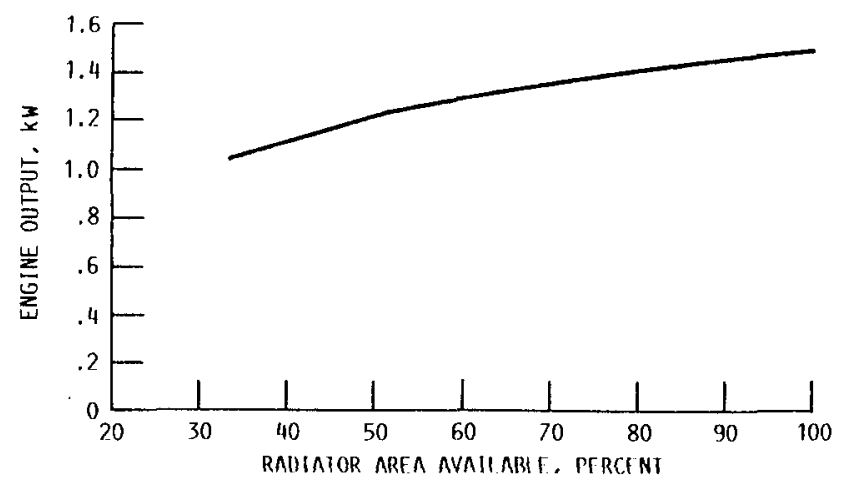

FIGIIRE 3. - ETFECT OF REDUCTION OF RADIATOR AREA ON ENGINE PERFORMANCE.
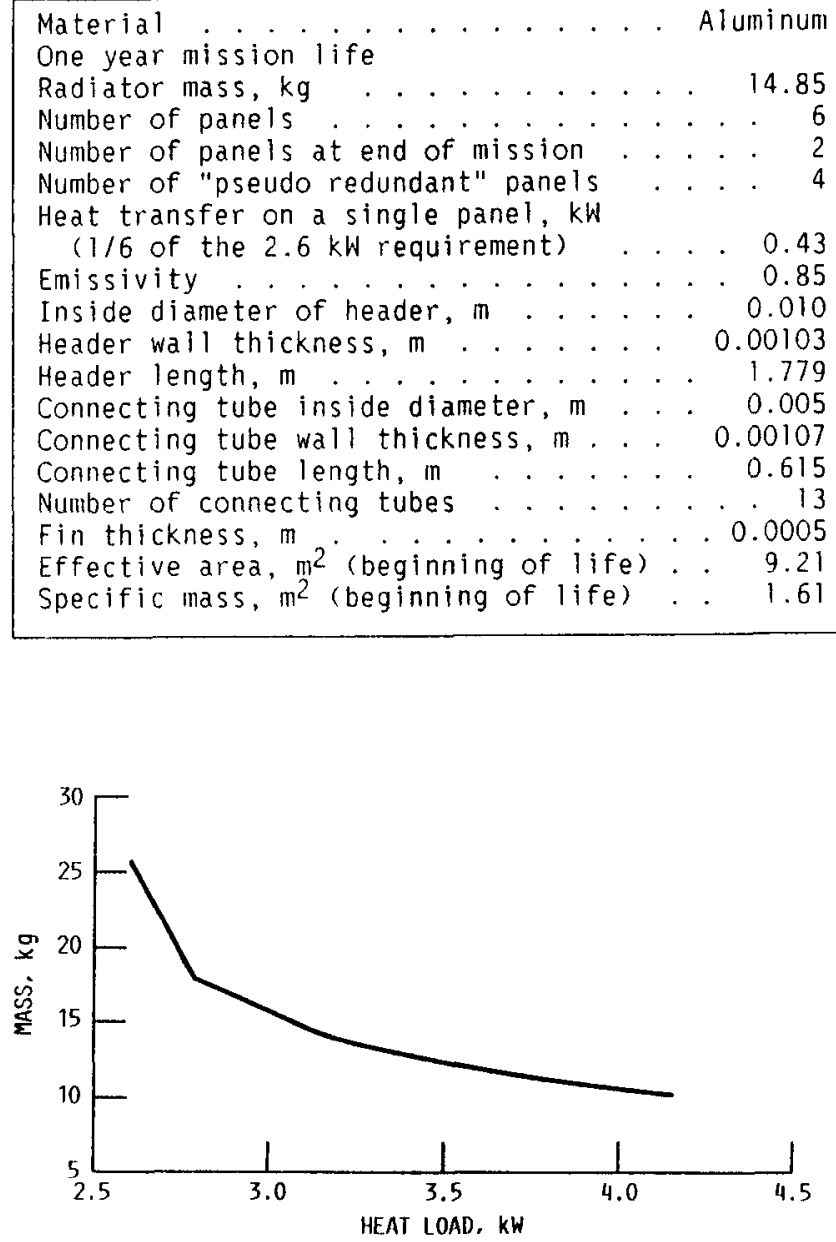

TIGURF 2. - OPIIMIZED SIZE AND MASS OF RADIATORS FOR STIRLING ENGINE RADIATOR, BASIC DESIGN APPROACH.

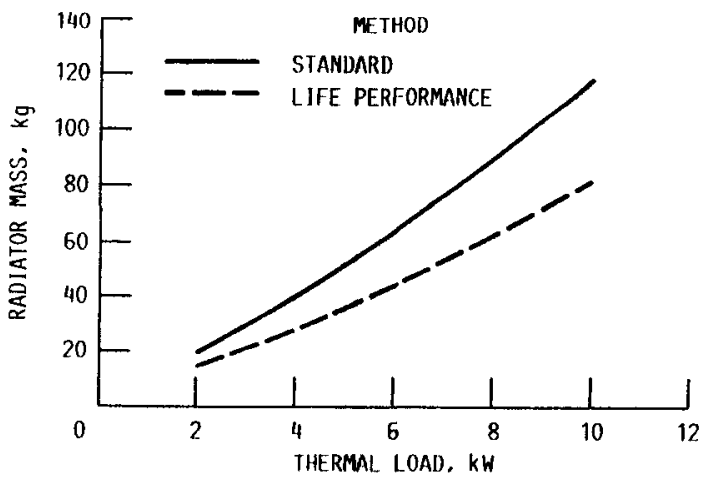

FIGURE 4. - EFFECI OF VARYING THERMAL LOAD ON RADIATOR MASS FOR IWO DESIGN APPROACHES ASSUMING A ONE YEAR DESIGN LIFE. 


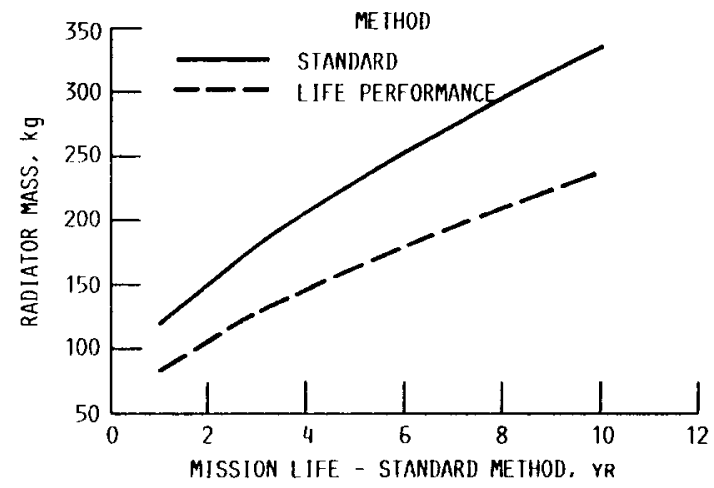

FIGURE 5. - EFFECT OF VARYING MISSION LIFE ON RADIATOR MASS FOR TWO DESIGN APPROACHES ASSUMING A $10 \mathrm{~kW}$ THERMAL LOAD. 


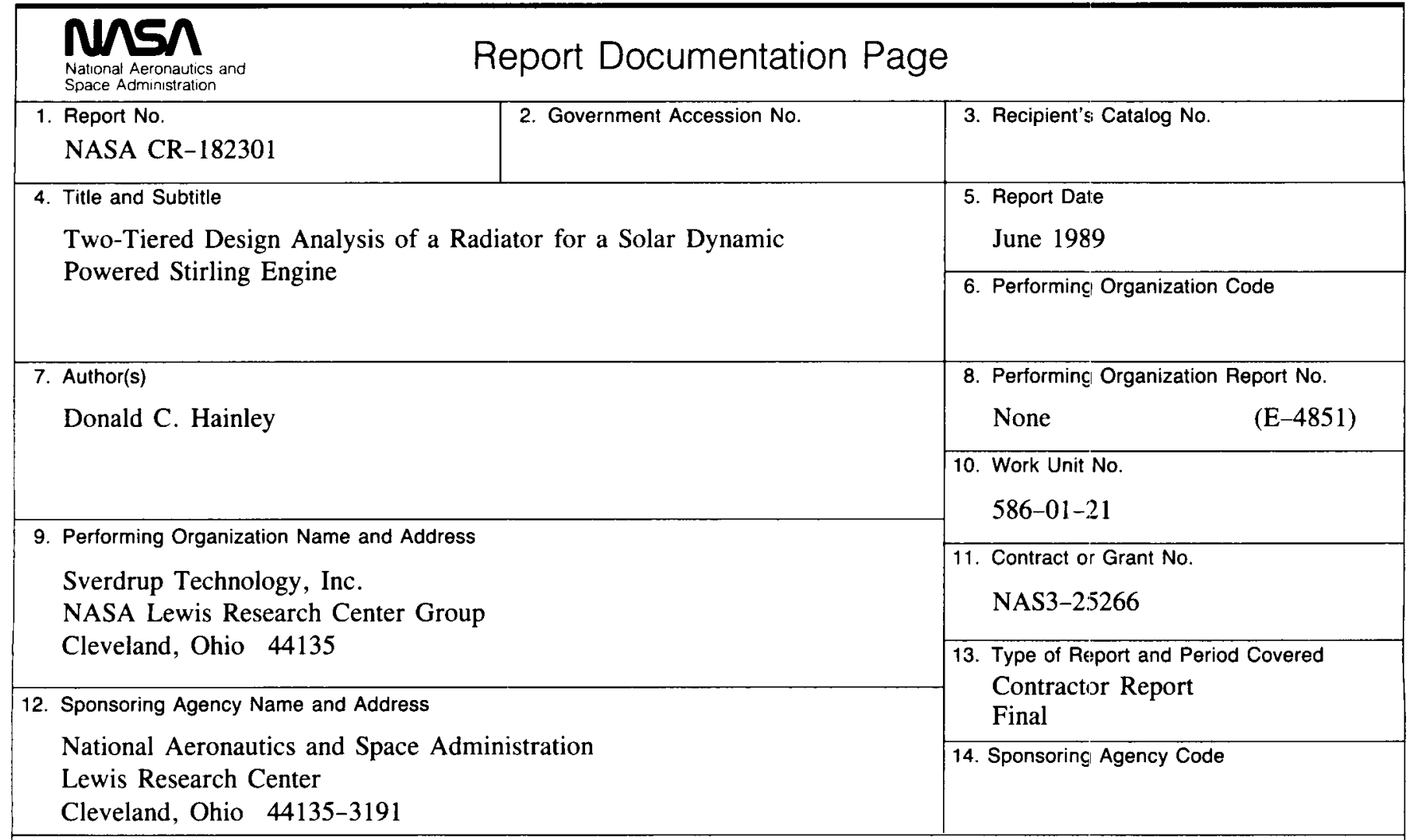

15. Supplementary Notes

Project Manager, Albert J. Juhasz, Power Technology Division, NASA Lewis Research Center. Prepared for the 24th Intersociety Energy Conversion Engineering Conference cosponsored by the IEEE, AIAA, ANS, ASME, SAE, ACS, and AIChE, Washington, D.C., August 6-11, 1989.

\section{Abstract}

a study done using two separate design approaches for a pumped loop radiator used to transfer heat from the cold end of a solar dynamic powered Stirling engine. The first approach uses a standard method to determine radiator requirements to meet specified end of mission conditions. Trade-off studies conducted for the analysis are included. Justification of this concept within the specified parameters of the analysis is provided. The second design approach used determines the life performance of the radiator/Stirling system. In this approach, the system performance was altered by reducing the radiator heat transfer area. Performance effects and equilibrium points were determined as radiator segments were removed. This simulates the effect of loss of radiator sections due to micro-meteoroid and space debris penetration. The two designs were compared on the basis of overall system requirements and goals.

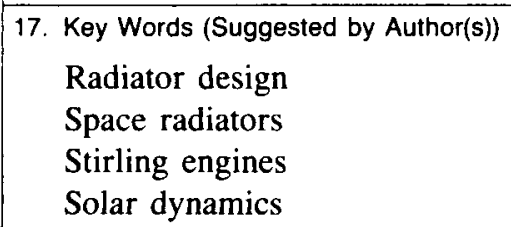

18. Distribution Statement

Unclassified - Unlimited

Subject Category 18 